\title{
Design and modeling of a synchronous renewable energy generation system
}

\author{
Wiem Nhidi ${ }^{1}$, Souhir Tounsi ${ }^{2}$, Mohamed Salim Bouhlel ${ }^{3}$ \\ ${ }^{1}$ National School of Engineers of Gabes (ENIG), Sfax University, SETIT Research Unit, Gabès, Tunisia \\ ${ }^{2}$ Ational School of Electronics and Telecommunications of Sfax, Sfax University, SETIT Research Unit, Sfax, Tunisia \\ ${ }^{3}$ Institut Supérieur de Biotechnologie de Sfax (ISBS), Sfax University, SETIT Research Unit, Sfax, Tunisia
}

Email address:

nhidiwiem@gmail.com (W. Nhidi), souhir.tounsi@isecs.rnu.tn (S. Tounsi), medsalim.bouhlel@enis.rnu.tn (M. S. Bouhlel)

\section{To cite this article:}

Wiem Nhidi, Souhir Tounsi, Mohamed Salim Bouhlel. Design and Modeling of a Synchronous Renewable Energy Generation System. American Journal of Electrical Power and Energy Systems. Special Issue: Design and Monitoring of Renewable Energy Systems.

Vol. 4, No. 3-1, 2015, pp. 6-11. doi: 10.11648/j.epes.s.2015040301.12

\begin{abstract}
In this paper we describe a design and modeling methodology of synchronous generation system for renewable energy. Our choice fell on a synchronous generator structure with permanent magnet and axial flux simple to manufacturing to reduce the production cost of the energy generation system. The modeling approach presented leads to a scientific results of high level and opens the line of research to the study of the optimization of the energy recovered by the energy accumulator.
\end{abstract}

Keywords: Design, Modeling, Synchronous Generator, Renewable Energy, AC-DC Converter, Matlab-Simulink, Simulations

\section{Introduction}

In light of strong oil crises and undeniable air pollution problem, the generation of renewable energy from wind has become a current project. In this context several research addresses this problem. Our work is situated in this context too. The general problem of wind turbine systems is in generally the low efficiency due to total losses in energy conversion chain. This study illustrates a parameterized model of the energy generation system that can be a problem of recovered energy optimizing.

In this direction, this paper is organized as follows:

- The first part concern the presentation of the conversion chain structure.

- The second part presents the different models of the conversion chain.

- And the third part presents the results of simulations.

\section{Conversion Chain Structure}

The conversion chain (figure 1) has a propeller to recover the energy generated by wind. This mechanical energy is converted into an alternating electrical energy via the synchronous generator. The electrical energy developed is also converted into a continuous power through a three-phase rectifier. Finally, the continuous energy is elevated via a DC-DC converter to optimize the energy recovered by the battery [1-5].

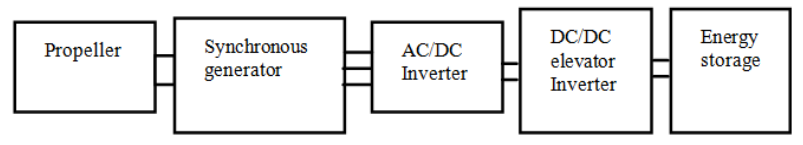

Figure 1. Structure of the renewable enrgy system.

\section{Movement Equation}

The equation of motion of the shaft of the synchronous generator is given by the following relationship:

$$
\mathrm{J} \times \frac{\mathrm{d} \Omega}{\mathrm{dt}}=\mathrm{T}_{\mathrm{em}}-\frac{\mathrm{P}_{\text {iron }}}{\Omega}-\frac{\mathrm{P}_{\mathrm{m}}}{\Omega}
$$

Where $\mathrm{J}$ is the moment of inertia of the rotating parts, $\mathrm{P}_{\text {iron }}$ are the iron losses, $\Omega$ is the angular velocity of the propeller, $\mathrm{P}_{\mathrm{m}}$ are the mechanical losses and $\mathrm{T}_{\mathrm{em}}$ is the torque on the shaft of the synchronous generator.

$$
\mathrm{T}_{\mathrm{em}}=\frac{1.918 \times \mathrm{r}_{\mathrm{p}}{ }^{2} \mathrm{~V}^{3}}{\Omega}
$$

Where $r_{p}$ is the pale length and V is the wind speed. 
Mechanical losses are expressed by the following relationship [1-5]:

$$
\mathrm{P}_{\mathrm{m}}=\mathrm{s}+\mathrm{k} \times \Omega+\gamma \times \Omega^{2}
$$

Where $\mathrm{s}$ is a dry friction coefficient, $\mathrm{k}$ is a viscous friction coefficient, and $\gamma$ is a coefficient of fluid friction.

The iron losses are expressed by the following relationship [1-5]:

$$
\mathrm{P}_{\text {iron }}=1.1 \times\left(\frac{\mathrm{f}}{50}\right)^{1.5}\left(\mathrm{M}_{\mathrm{cs}} \times \mathrm{B}_{\mathrm{cs}}^{2}+\mathrm{M}_{\mathrm{ds}} \times \mathrm{B}_{\mathrm{d}}^{2}\right)
$$

Where $\mathrm{f}$ is the frequency of the currents delivered by the synchronous generator, $M_{c s}$ is the stator yoke mass, $M_{d s}$ is the mass of stator teeth, $B_{c s}$ is the stator yoke flux density and $B_{d}$ is the stator teeth flux density.

The equation of motion is implanted within the Matlab-Simulink environment according to Figure 2.

\section{AC-DC Conversion}

The torque recovered on the generator shaft allows the drive the latter to the angular velocity $\Omega$. This movement allows the induction of three-phase trapezoidal electromotive forces. These three electromotive forces are converted into a DC voltage filtered by a capacitance of high value by a three-phase rectifier.

The Simulink model of the conversion system of mechanical energy into a continuous electrical energy is illustrated by the following figure [1-3]:

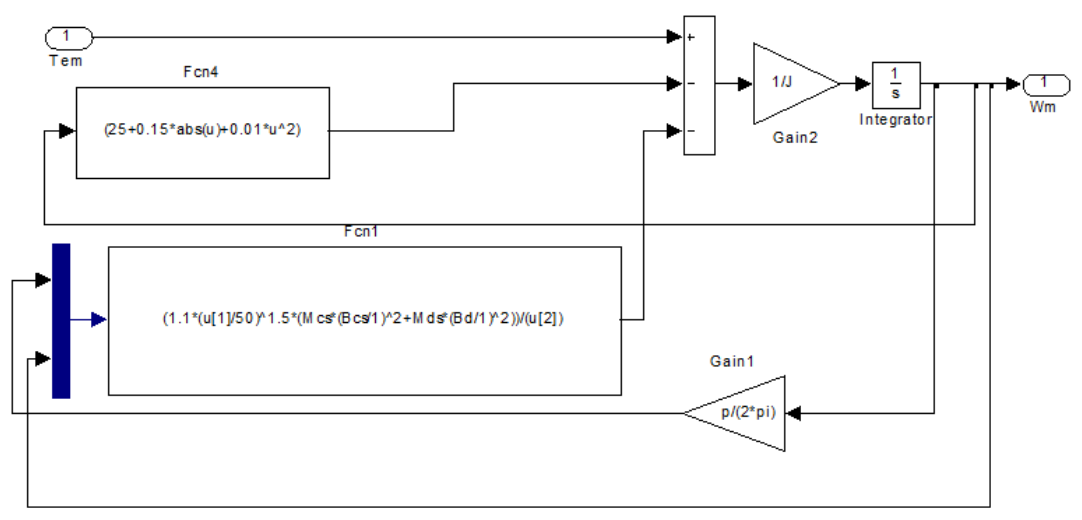

Figure 2. Simulink model of the movement equation.

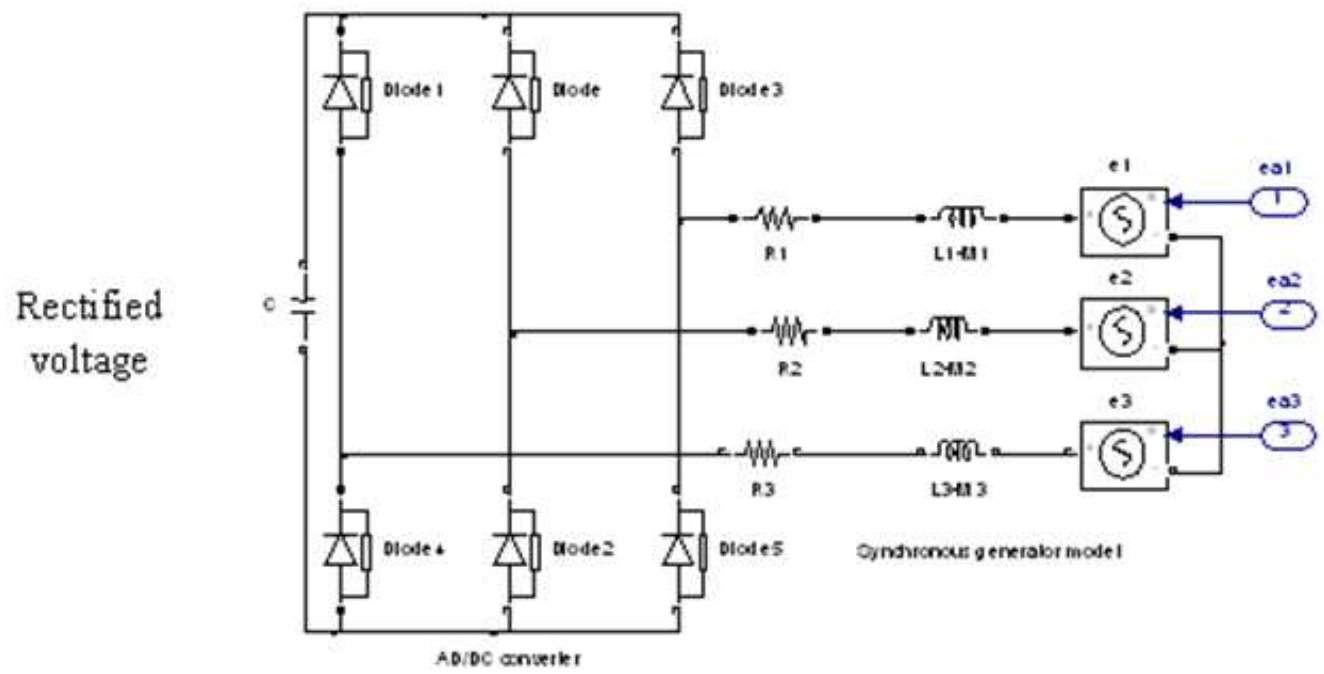

Figure 3. Simulink model of AC-DC conversion system.

The three electromotive forces are estimated from the following three equations:

$$
\begin{gathered}
a=\cos \left(p \times \Omega \times t+\frac{\pi}{2}\right) \\
b=\cos \left(p \times \Omega \times t-\frac{2 \times \pi}{3}+\frac{\pi}{2}\right)
\end{gathered}
$$

$$
c=\cos \left(p \times \Omega \times t-\frac{4 \times \pi}{3}+\frac{\pi}{2}\right)
$$

The models of the electromotive forces $\left(\mathrm{e}_{1}, \mathrm{e}_{2}, \mathrm{e}_{3}\right)$ are estimated from the following algorithm:

$$
\begin{aligned}
& \{\text { Begin } \\
& \text { if } \\
& a>1 / 2 \text {; }
\end{aligned}
$$




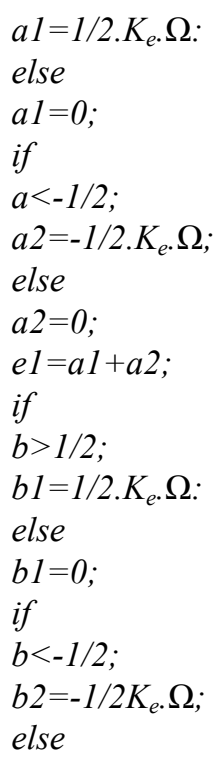

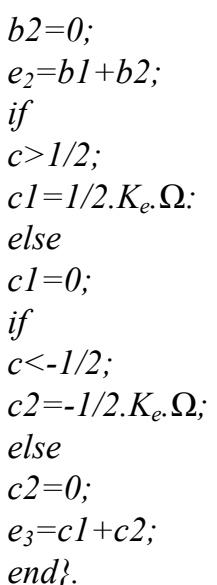

With $\mathrm{K}_{\mathrm{e}}$ is the electromotive forces constant, $\Omega$ is the motor angular speed and $\mathrm{p}$ is the number of pole pairs.

The Simulink model of the electromotive forces is illustrated by the figure 4 .

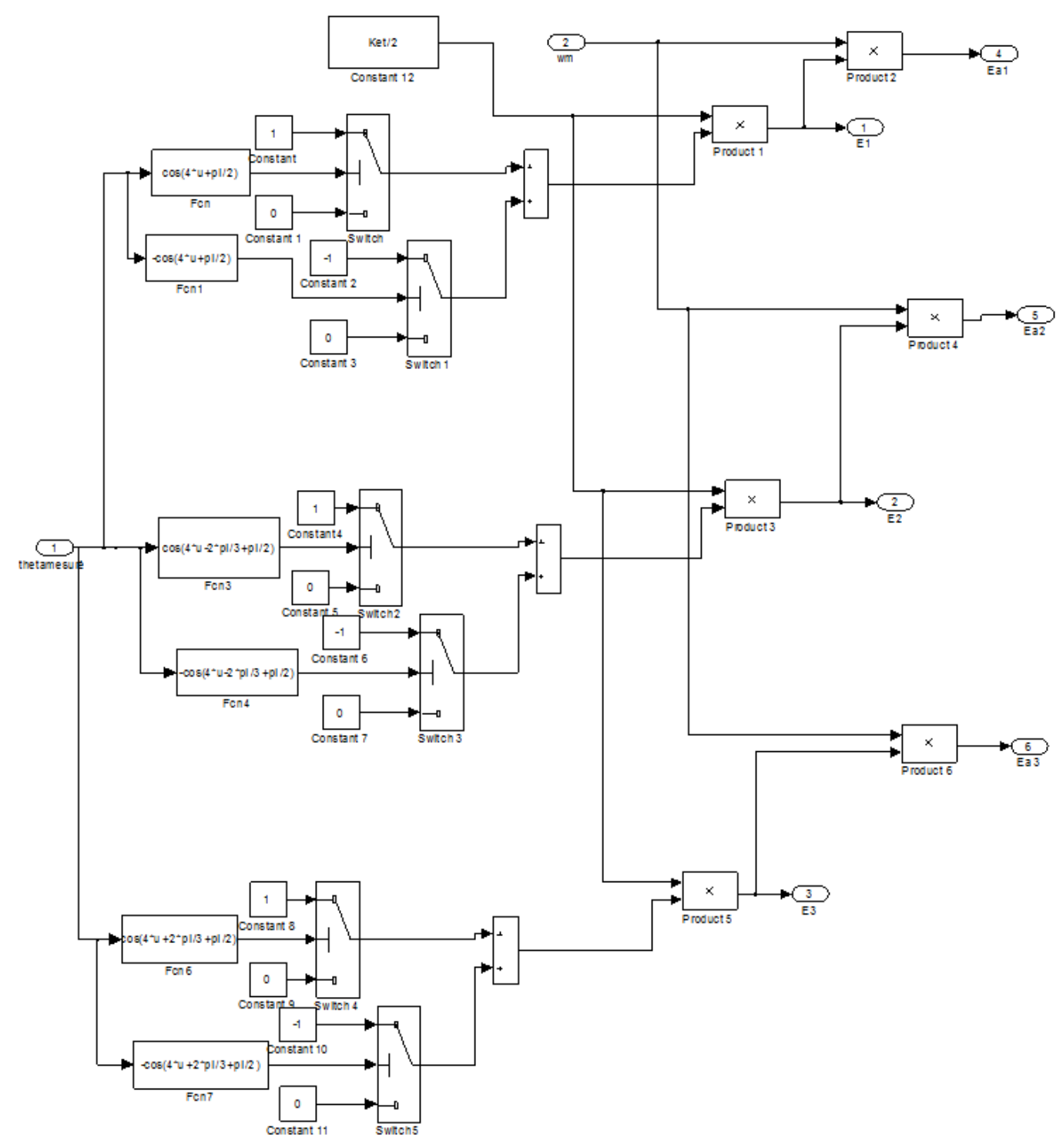

Figure 4. Simulink model of the electromotive forces. 


\section{DC-DC Conversion}

A DC-DC boost converter (figure 5) capable of converting the rectified and filtered voltage into to a higher voltage amplitude is used in order to optimize the recovered energy. The cyclic ratio of the converter control signal is optimized following several simulations in order to maximize the energy recovered by the energy accumulator.

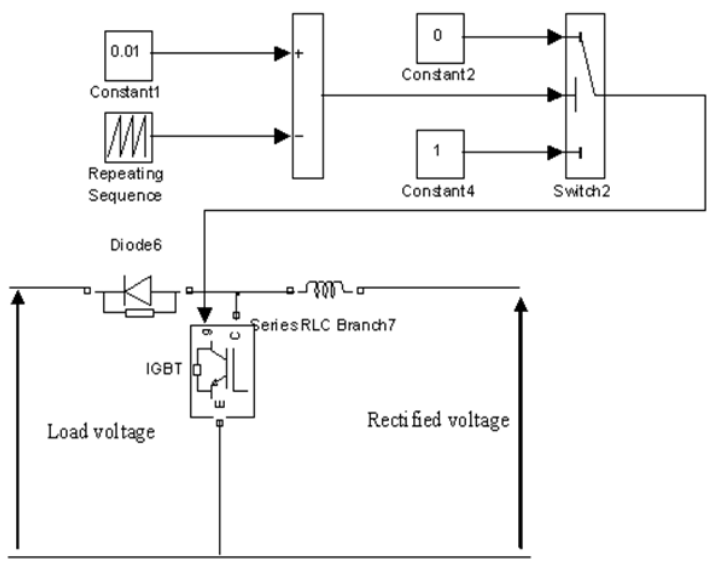

Figure 5. DC-DC elevator inverter.

\section{Energy Accumulator}

The energy accumulator comprises batteries in parallel with supper capacitor to increase the storage capacity. The Simulink model of the battery is illustrated by figure 6 [5].

$\mathrm{C} 2$ is a capacitor for holding into account the transitional regim and $\mathrm{R}_{1}$ is the internal resistance of the battery.

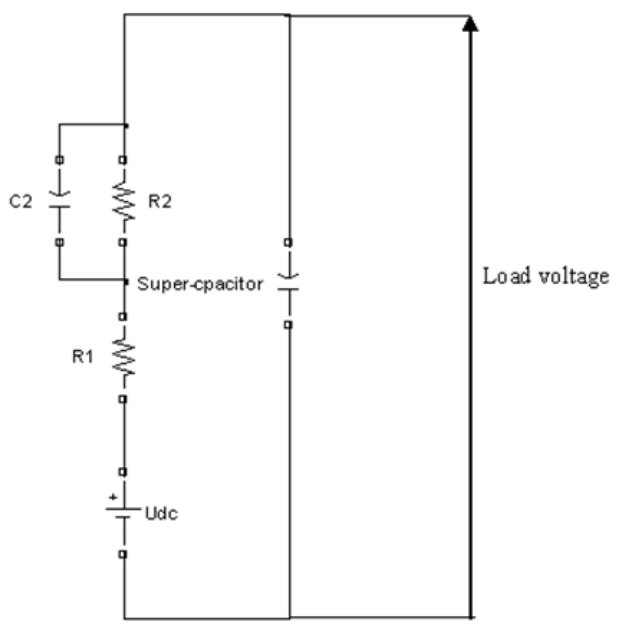

Figure 6. Simulink model of the energy accumulator.

\section{Global Model of Renewable Energy Generation System}

The global model of the energy generation system is based on the connection of the different Simulink models of the components making up this chain (Figure 7).

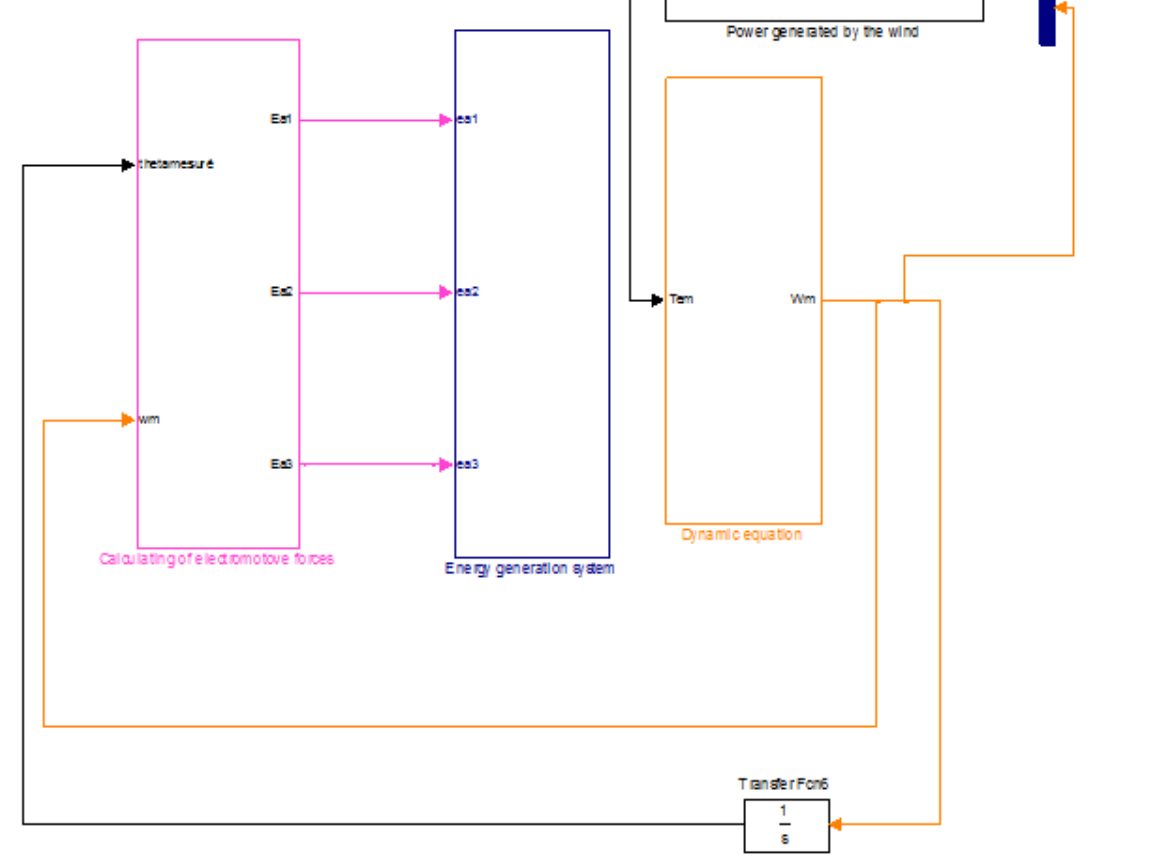

Figure 7. Simulink model of the global system. 


\section{Simulations Results}

The evolution of the wind speed is illustrated in Figure 8.

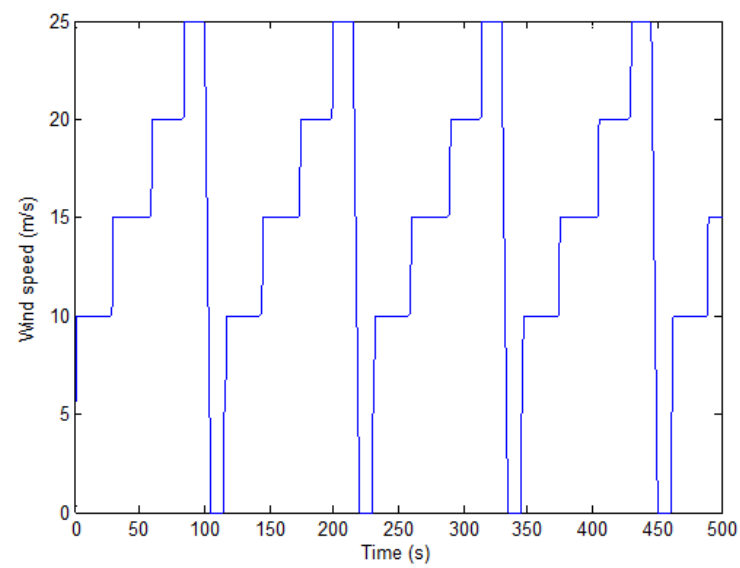

Figure 8. Evolution of the wind speed.

The evolution of the angular speed of the generator shaft is illustrated in Figure 9.

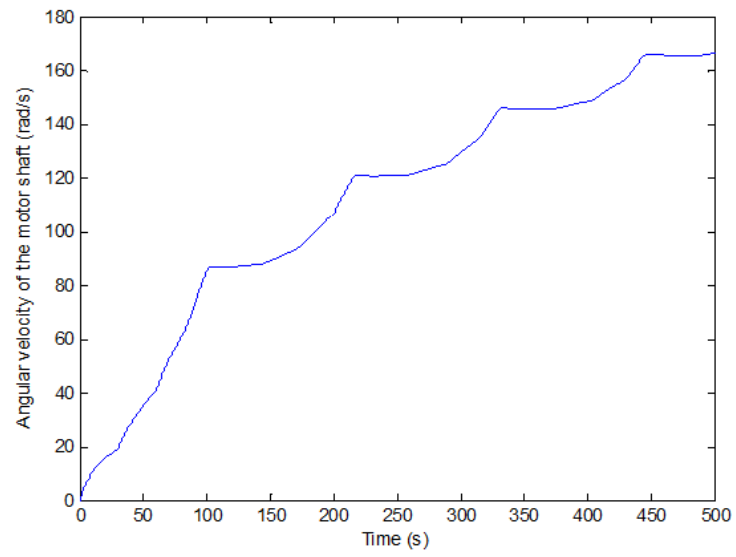

Figure 9. Evolution of the angular speed of the generator shaft.

The three-phase voltage system generated by the synchronous generator is shown in Figure 10.

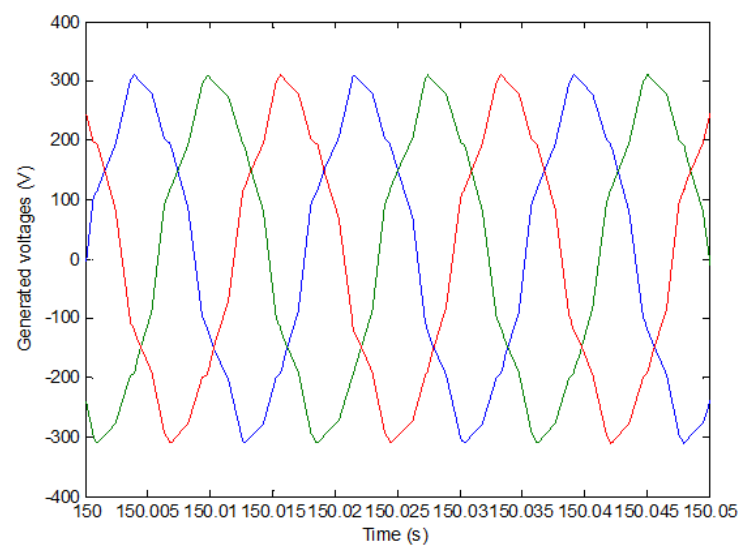

Figure 10. Phase voltages generated by the synchronous generator.

The phase currents generated by the synchronous generator are illustrated by Figure 11 .

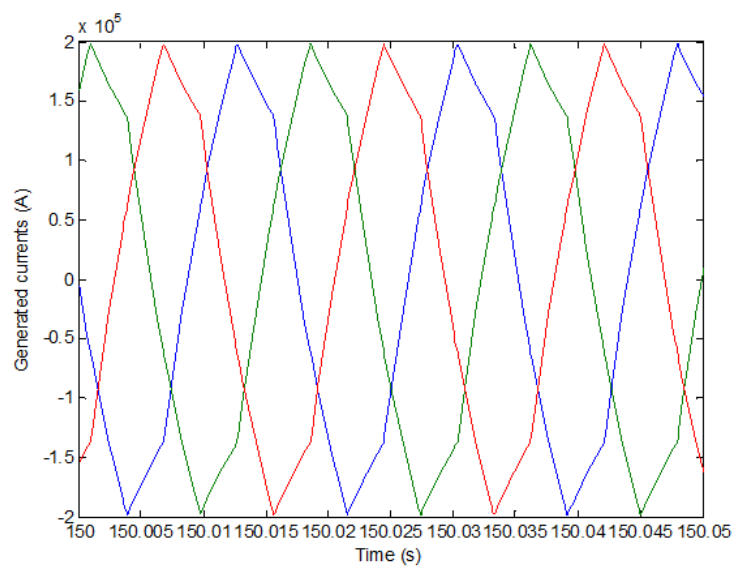

Figure 11. Phase currents generated by the synchronous generator.

The slight deformation in the shapes of voltages and currents is mainly due to the presence of a strong inertia of the rotating parts and the strong phase inductance.

The evolution of the load voltage is illustrated by the figure 12.

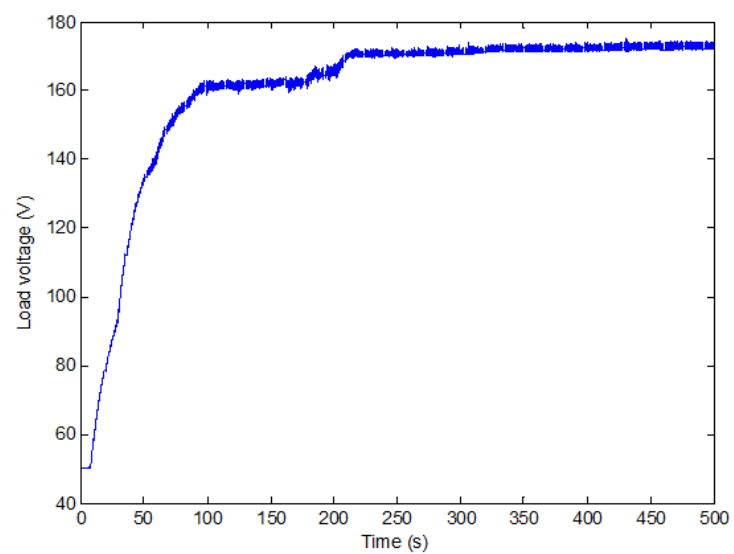

Figure 12. Evolution of the load voltage.

The evolution of the load current is illustrated by the figure 13.

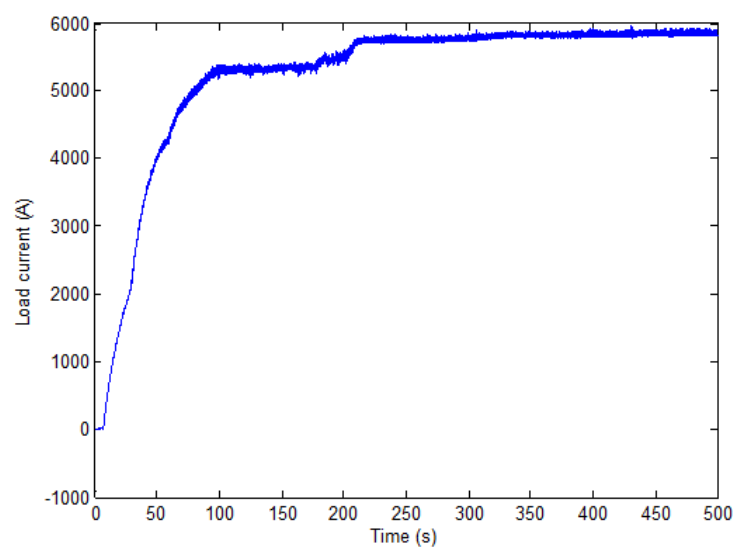

Figure 13. Evolution of the load current. 
The generated and recovered powers are illustrated by figure 14 .

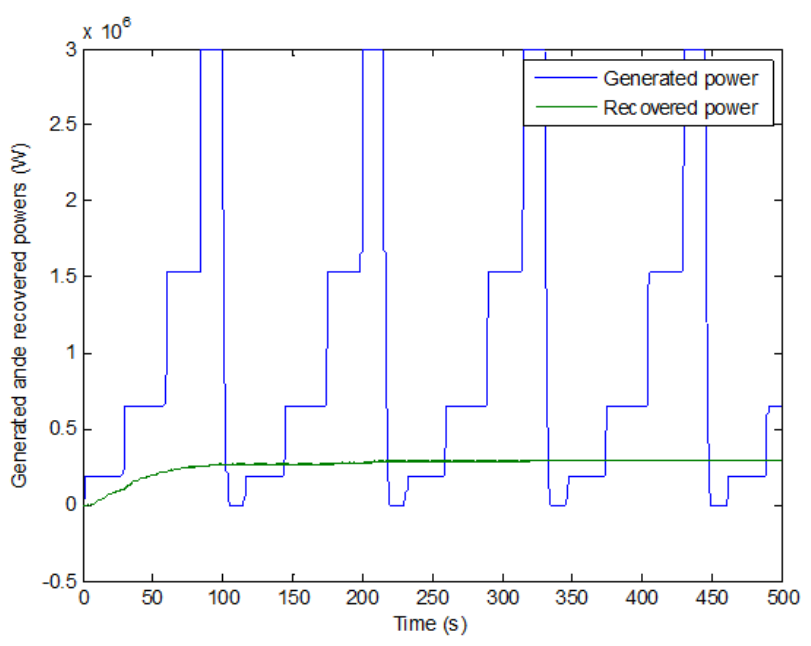

Figure 14. Generated and recovered powers.

The recovered energy is illustrated by figure 15 .

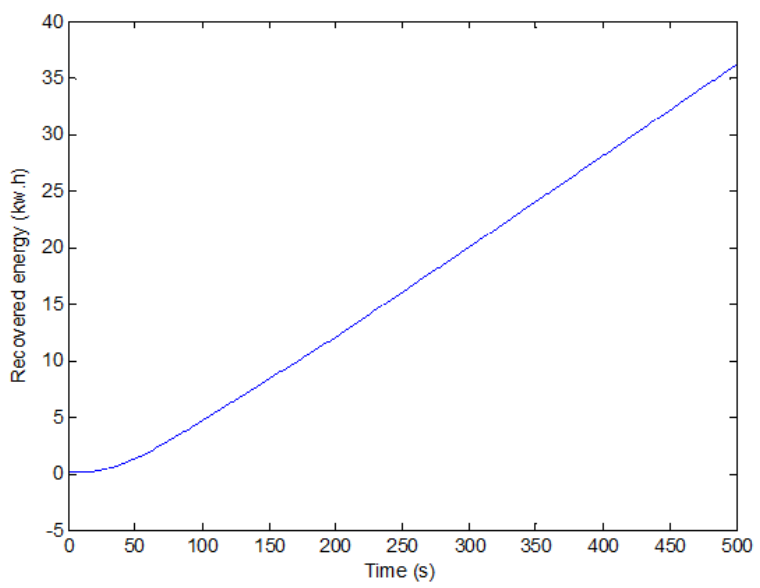

Figure 15. Recovered energy.

\section{Conclusion}

In this paper we present a methodology for the design and modeling of a parameterized system for generating renewable energy. The implementation of the energy generation chain global model under the Matlab-Simulink environment leads to the scientific results of very good level. Being parametrized, the developed model poses an optimization problem of the recovered energy for future research work.

\section{References}

[1] S. TOUNSI « Comparative study of trapezoïdal and sinusoïdal control of electric vehicle power train», International Journal of Scientific \& Technology Research (IJSTR), Vol. 1, Issue 10, Nov 2012.

[2] M. HADJ KACEM, S. TOUNSI, R. NEJI «Control of an Actuator DC Energy-saving Dedicated to the Electric Traction», International Journal of Computer Applications: IJCA (0975 8887) Volume 54-No.10, pp. 20-25, September 2012.

[3] S. TOUNSI "Control of the Electric Vehicles Power Chain with Electromagnetic Switches Reducing the Energy Consumption», Journal of Electromagnetic Analysis and Applications (JEMAA) Vol.3 No.12, Deember 2011.

[4] S. TOUNSI, M. HADJ KACEM et R. NEJI « Design of Static Converter for Electric Traction », International Review on Modelling and Similations (IREMOS) Volume 3, N. 6, December 2010, pp. 1189-1195. [8] S. TOUNSI et R. NEJI: "Design of an Axial Flux Brushless DC Motor with Concentrated Winding for Electric Vehicles", Journal of Electrical Engineering (JEE), Volume 10, 2010 - Edition: 2, pp. 134-146.

[5] S. TOUNSI, R. NEJI, and F. SELLAMI: "Design Methodology of Permanent Magnet Motors Improving Performances of Electric Vehicles", International Journal of Modelling and Simulation (IJMS), Volume 29, N 1, 2009. 